\title{
Thermogenic effect of bronchodilators in patients with chronic obstructive pulmonary disease
}

\author{
Luc Burdet, Benoît de Muralt, Yves Schutz, Jean-William Fitting
}

\begin{abstract}
Background - Patients with chronic obstructive pulmonary disease (COPD) are frequently malnourished and have increased resting energy expenditure (REE). An increase in the work of breathing is generally considered to be the main cause of this hypermetabolism, but other factors may also be implicated. Bronchodilators may decrease the work of breathing by reducing airway obstruction, but $\beta_{2}$ adrenergic agents have a thermogenic effect. The aim of this study was to determine the effect of salbutamol and ipratropium bromide administration on REE in patients with COPD.
\end{abstract}

Methods - Thirteen patients $(10$ men $)$ of mean (SD) age 68.3 (7.3) years and forced expiratory volume in one second $\left(\mathrm{FEV}_{1}\right)$ $39.0(17.0) \%$ predicted were studied on three consecutive days. The REE was measured by indirect calorimetry at 30 , 60,120 , and 180 minutes after double blind nebulisation of either salbutamol, ipratropium bromide, or placebo in random order.

Results - FEV 1 increased both after salbutamol and after ipratropium. The difference in the mean response between salbutamol and placebo over 180 minutes was $+199 \mathrm{ml}(95 \% \mathrm{CI}+104$ to +295$)$. The difference in mean response between ipratropium and placebo was $+78 \mathrm{ml}(95 \%$ CI +2 to +160$)$. REE increased after salbutamol but was not changed after ipratropium. The difference in mean response between salbutamol and placebo was $+4.8 \%$ of baseline REE $(95 \% \mathrm{CI}+2.2$ to +7.4$)$. Heart rate increased after salbutamol but not after ipratropium. The difference in the mean response between salbutamol and placebo was +5.5 beats/ $\min (95 \% \mathrm{CI}+2.6$ to +8.4$)$.

Conclusion - Salbutamol, but not ipratropium bromide, induces a sustained increase in the REE of patients with COPD despite a reduction in airway obstruction. (Thorax 1997;52:130-135)

Keywords: chronic obstructive pulmonary disease, energy expenditure, bronchodilating drugs.

Correspondence to Dr J-W Fitting.

Received 23 November 1995 Returned to authors

4 March 1996

Revised version received

23 July 1996

Accepted for publication

23 July 1996

Weight loss may be a feature in some patients with chronic obstructive pulmonary disease $(\mathrm{COPD})^{12}$ and is associated with an increased mortality. ${ }^{3}$ As the nutritional state is a balance between energy and substrate intake and energy expenditure and substrate utilisation, any factor which alters this balance may have detrimental effects. Using standard methods of indirect calorimetry, previous studies have found an increased resting energy expenditure (REE) in patients with COPD. ${ }^{4-8}$ This has been attributed mainly to an increased cost of breathing, ${ }^{9}$ but several other factors have been suspected, ${ }^{10}$ including drugs. ${ }^{112}$ Inhaled anticholinergic drugs are not known to induce a thermogenic effect, but in normal subjects oral theophylline ${ }^{13}$ and oral and inhaled $\beta_{2}$ adrenergic drugs ${ }^{11}{ }^{14}$ increase REE. A similar thermogenic effect can be expected in patients with chronic airflow limitation. On the other hand, bronchodilating drugs may decrease the work of breathing by reducing airway obstruction, and thereby the REE. Thus, the net thermogenic effect of bronchodilators is unknown in COPD and may differ according to the type of pharmacological agent.

This study was undertaken to examine whether bronchodilators had a thermogenic effect in patients with stable COPD. To test this hypothesis we measured the effects on REE of three substances administered by nebulisation $-\mathrm{a} \beta_{2}$ adrenergic bronchodilator (salbutamol), an anticholinergic bronchodilator (ipratropium bromide), and placebo.

\section{Methods}

SUBJECTS

Thirteen patients with stable COPD were studied at the end of a stay in the Pulmonary Rehabilitation Centre of the Rolle Hospital. Functional criteria for inclusion were defined as a ratio of forced expiratory volume in one second $\left(\mathrm{FEV}_{1}\right)$ to forced vital capacity (FVC) of $<70 \%$ of the predicted value and reversibility of $<10 \%$ of predicted $\mathrm{FEV}_{1}$ after inhalation of $400 \mathrm{mg}$ salbutamol. All patients could tolerate withdrawal of bronchodilators for 16 hours and all were apyrexial at the time of the study. None of the patients had evidence of diabetes, cancer, digestive or renal disease. The protocol was approved by the ethical committee of our institution and all patients gave their written informed consent.

\section{NUTRITIONAL STATUS}

Each patient was weighed and measured at the beginning of the study. The body weight was expressed as percentage of ideal body weight (IBW), as defined by the mid point of the 
weight range for height in the table of the Metropolitan Life Insurance Company. ${ }^{15}$ The body mass index (BMI) was calculated by dividing the body weight $(\mathrm{kg})$ by the height squared $\left(\mathrm{m}^{2}\right)$. Body fat content was estimated by measuring skinfold thickness at four sites bicipital, tricipital, subscapular, and suprailiac $^{1617}$ - with a caliper (Lange Caliper, Cambridge Scientific Industries Inc, Cambridge, Massachusetts, USA). All measurements were made in triplicate by the same investigator. Fatfree mass (FFM) was calculated by subtracting the fat content from the body weight. The fatfree mass was also assessed by bioelectrical impedance analysis by measuring the whole body resistance (Z-mètre, Division Autonome d'Electronique Médicale CHUV, Lausanne, Switzerland) to a low alternating current passing between the right wrist and the right ankle. ${ }^{18}$ The impedance was measured in triplicate and the fat-free mass calculated using the equation of Schols et al. ${ }^{19}$

PULMONARY FUNCTION TESTS

Forced expiratory flow rates were measured by a mass flow anemometer (SensorMedics 2200 Pulmonary Function Laboratory, SensorMedics Corp, California, USA), and carbon monoxide transfer factor (TLCO) by the single breath method (SensorMedics). Arterial blood gas tensions were measured by a blood gas analyser (AVL Blood Gas Analyser 995 S, AVL Medical AG, Schaffhausen, Switzerland). During the experimental sessions forced expiratory flow rates were measured by a pneumotachometer (Multispiro SA/100, Medical Equipment Design Inc, California, USA). Reference values were those proposed by Quanjer et $a .^{20}$

\section{ENERGY EXPENDITURE}

REE was measured by indirect calorimetry with a transparent ventilated hood placed over the head of the patient. A constant fraction of the air flowing through the hood was collected for analysis in an indirect calorimetry device (Deltatrac, Datex Instrumentarium Corp., Helsinki, Finland). Oxygen concentration was measured by a paramagnetic oxygen sensor and carbon dioxide concentration by an infrared sensor. The energy expenditure (EE) was calculated from these values according to the method of Bursztein et al. ${ }^{21}$ The calorimetric measurements were continuously integrated over consecutive one minute intervals. The accuracy and precision of the calorimeter were assessed by an infusion test using nitrogen and carbon dioxide over a period of one hour and 48 minutes. The mean (SD) measured oxygen consumption was 100.6 (1.7)\% of the actual value and measured carbon dioxide production was $101.3(1.4) \%$ of the actual value. The device was calibrated immediately before each measurement with a reference gas mixture.
HEART AND RESPIRATORY RATES

Heart rate was measured continuously during the test by a portable device (Baumann Construction Electronique Médicale, Fleurier, Switzerland) and the mean value was calculated in the last 10 minutes of each calorimetry period. The respiratory rate was counted by the attending physician looking at the patient's respiratory movements during three periods of two minutes in each calorimetry period.

THEOPHYLLINE LEVELS

On the first day of the study the theophylline concentration was measured with a polarisation fluorescence system (TDx, Abott Laboratories, North Chicago, Illinois, USA) in the serum of patients who were treated with xanthine derivatives. Blood samples were taken in the morning at the predicted trough levels of theophylline.

EXPERIMENTAL PROTOCOL

The study was performed in three sessions on three consecutive mornings after an overnight fast. For the six patients taking xanthine drugs the dose was unchanged for at least three days before the study and during the study. All patients were requested to stop any oral $\beta_{2}$ adrenergic drug or inhaled long acting $\beta_{2}$ adrenergic drug 24 hours before the beginning of the study. They did not receive short acting $\beta_{2}$ adrenergic drugs for at least 10 hours before each measurement session. During each session, after 20 minutes of rest, calorimetry measurements were carried out, the patients lying supine with the head elevated at 30 degrees and placed in the hood. The patients were asked to remain completely quiet. They did not watch television or listen to the radio during the measurements. The investigators ensured that the patients did not move or sleep. After initiating calorimetry, time was allowed for energy expenditure (EE) to stabilise, which usually occurred within 15 minutes. The EE was measured until at least 15 minutes of steady state were obtained to determine the REE. After these initial measurements the patients received a different treatment in each session in random order, consisting of either $5 \mathrm{mg}$ salbutamol, $0.5 \mathrm{mg}$ ipratropium bromide, or placebo $(\mathrm{NaCl} 0.9 \%)$, administered by wet nebulisation (inhalation device Pari-Master with Pari-LC Plus atomizer, Pari-Werk GmbH, Starnberg, Germany). The doses of salbutamol and ipratropium were chosen after a review of the literature ${ }^{22-24}$ which suggested that they were equipotent in terms of bronchodilation. The randomisation was made in blocks of six patients since there were six possible orders of administration of the three treatments. The solutions were prepared by a member of staff not involved in the protocol who randomly chose one of the six possible orders of administration and prepared $2 \mathrm{ml}$ of solution for nebulisation containing either salbutamol, ipratropium, or placebo in three different test tubes labelled 1,2, and 3 for the three days of the test. 
The time at the end of nebulisation was taken as T0. EE was then measured for three periods of at least 15 minutes, ending at 30, 60, 120, and 180 minutes after T0. Since it was not possible to ensure that the steady state period would end exactly on time, a maximal 10 minute delay was allowed. After each calorimetry period the hood was removed and spirometric tests were performed (T30, T60, T120, T180). Between periods of measurement the patients were allowed to sit on a chair next to the bed, but without exerting themselves. They did not receive any other medication or food during the course of each morning of testing. In the afternoons and evenings they could eat normally, follow the rehabilitation programme, and take their usual treatment other than the drugs mentioned above.

The REE was expressed in $\mathrm{kcal} / 24$ hours and compared with predicted basal metabolic rate (BMR) according to Harris and Benedict. ${ }^{25}$ Each day the change in REE after the treatment was expressed as a percentage of the baseline value measured on the same day.

STATISTICAL ANALYSIS

The mean baseline REE values during the three measurement sessions were compared by repeated measures ANOVA. Post-tests were then performed with a Bonferroni $t$ test as described by Glantz. ${ }^{26}$ For each parameter $\left(\mathrm{FEV}_{1}, \mathrm{REE}\right.$, heart rate, respiratory rate) the effect of each treatment (salbutamol, ipratropium, placebo) was assessed by calculating for each subject the area under the curve which can be interpreted as the cumulative response to treatment. ${ }^{27}$ The area under the curve was divided by the duration of the study (180 minutes) to obtain the mean response as the summary measure. Differences between treatments were then compared using repeated measures ANOVA, followed by paired $t$ tests to compare salbutamol and ipratropium with placebo. The relationship between the maximal change in REE after bronchodilator and the baseline REE was analysed by linear regression. The baseline REE was compared between patients receiving theophylline and those not receiving theophylline by a two-tailed unpaired $t$ test. The increase in REE 60 minutes after salbutamol in patients receiving theophylline was compared with the increase measured in patients who did not receive theophylline by a two-tailed unpaired $t$ test. Significance was determined at the 5\% level. All reported values are means (SD).

\section{Results}

NUTRITIONAL STATUS

Two patients were obese (body weight $148.5 \%$ and $158.0 \%$ of IBW) and two were underweight ( $85.6 \%$ and $89.0 \%$ of IBW). The mean weight of the remaining nine patients was $109.4 \%$ of IBW and their mean BMI was $24.4 \mathrm{~kg} / \mathrm{m}^{2}$ (table $1)$.
Table 1 Mean (SD) physical characteristics of the patients $(n=13)$

\begin{tabular}{ll}
\hline M:F & $10: 3$ \\
Age (years) & $68.3(7.3)$ \\
Height (cm) & $169(10)$ \\
Weight $(\mathrm{kg})$ & $72.8(18.5)$ \\
Weight $(\%$ of IBW) & $113(20)$ \\
BMI $\left(\mathrm{kg} / \mathrm{m}^{2}\right)$ & $25.2(4.8)$ \\
FFM $_{\mathrm{SF}}(\mathrm{kg})$ & $55.2(15.9)$ \\
FFM $_{\text {BIA }}(\mathrm{kg})$ & $57.9(11.9)$
\end{tabular}

$\mathrm{IBW}=$ ideal body weight $\mathrm{BMI}=$ body mass index $; \mathrm{FFM}_{\mathrm{SF}}=$ fat free mass calculated by the skinfold thickness method; FFM fat-free mass calculated by bioelectrical impedance analysis.

Table 2 Mean (SD) results of pulmonary function tests $(n=13)$

\begin{tabular}{ll}
\hline $\mathrm{FEV}_{1}(1)$ & $1.03(0.40)$ \\
$\mathrm{FEV}_{1}$ (\% predicted) & $39.0(17.0)$ \\
$\mathrm{FEV}_{1} / \mathrm{FVC}$ (\% predicted) & $45.9(13.1)$ \\
$\mathrm{TLCO}_{\text {(\% predicted) }}$ & $61.5(17.6)$ \\
$\mathrm{PaO}_{2}(\mathrm{kPa}$ mmHg) & $9.0(1.3) ; 67.6(9.5)$ \\
$\mathrm{PaCO}_{2}(\mathrm{kPa} ; \mathrm{mmHg})$ & $5.5(0.4) ; 41.6(3.3)$
\end{tabular}

FEV $\mathrm{FEV}_{1}=$ forced expiratory volume in one second; $\mathrm{FVC}=$ forced $\mathrm{PaCO}_{2}=$ arterial oxygen and carbon dioxide tensions.

All measures made at $400 \mathrm{~m}$ above sea level.

PULMONARY FUNCTION TESTS

The mean $\mathrm{FEV}_{1}$ was $39 \%$ predicted (range 24-76). Seven patients were emphysematous on the basis of a TLCO of $<60 \%$ of predicted values. Four patients were hypoxaemic $\left(\mathrm{PaO}_{2}\right.$ $\leq 8 \mathrm{kPa}$ or $60 \mathrm{mmHg}$ ) and three were hypercapnic $\left(\mathrm{PaCO}_{2} \geq 6 \mathrm{kPa}\right.$ or $45 \mathrm{mmHg}$ ) (table 2). The effects of the treatments on $\mathrm{FEV}_{1}$ are shown in fig 1 . Measurements could not be obtained in one patient because of intense coughing during each forced expiratory manoeuvre. The difference in mean response between salbutamol and placebo was $+199 \mathrm{ml}$ $(95 \%$ CI +104 to $+295 ; \mathrm{p}<0.001)$. The difference in mean response between ipratropium and placebo was $+78 \mathrm{ml}(95 \% \mathrm{CI}$ +2 to $+160 ; \mathrm{p}<0.05)$. As expected, the time course of bronchodilation was different with the two drugs, the maximum increase in $\mathrm{FEV}_{1}$ occurring 60 minutes after nebulisation of salbutamol and 180 minutes after nebulisation of ipratropium.

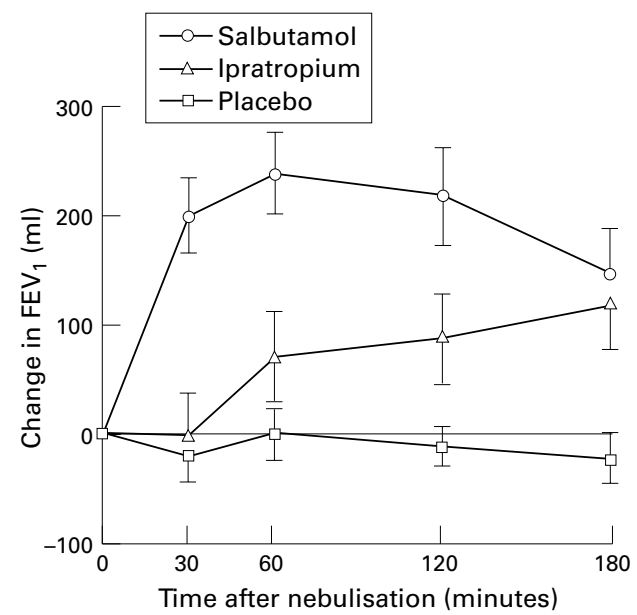

Figure 1 Mean change in forced expiratory volume in one second $(F E V)$ after nebulisation $(n=12)$. Bars $=$ SE. 


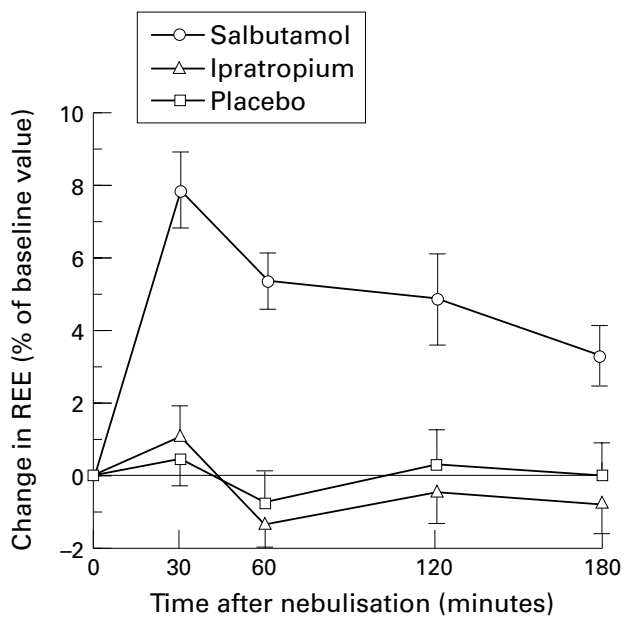

Figure 2 Mean relative change in resting energy expenditure (REE) after nebulisation $(n=13)$. Bars $=S E$.

ENERGY EXPENDITURE

Before nebulisation the mean REE of the three sessions was 1456 (260) kcal/24 hours which represented 100.2 (4.9)\% of the predicted value or $25.3(1.9) \mathrm{kcal} / 24$ hours $/ \mathrm{kg}$ of FFM measured by bioelectrical impedance (fig 2). There was no difference between the baseline REE on placebo (1460 (265) kcal/24 hours), ipratropium (1453 (257) kcal/24 hours), or salbutamol (1456 (266) kcal/24 hours). However, the baseline REE was $3.5 \%$ higher in the first measurement session than in the last $(\mathrm{p}<0.01)$.

REE increased after salbutamol but there was no change after ipratropium. The difference in the mean response between salbutamol and placebo was $+4.8 \%$ of baseline REE $(95 \%$ CI +2.2 to $+7.4 \% ; \mathrm{p}<0.002)$. The difference in the mean response between ipratropium and placebo was $-0.4 \%$ of the baseline REE $(95 \%$ CI -2.3 to $+1.5 \%$; NS).

\section{HEART AND RESPIRATORY RATES}

The mean heart rate before nebulisation was 74.5 (14.9) beats/minute. This increased after salbutamol but no change occurred after ipratropium (fig 3 ). The difference in the mean response between salbutamol and placebo was +5.5 beats $/ \mathrm{min}(95 \%$ CI +2.6 to +8.4 ; $\mathrm{p}<0.002)$. The difference in the mean response between ipratropium and placebo was -1.5 beats/min ( $95 \%$ CI -3.1 to 0.1 ; NS). Neither salbutamol nor ipratropium had any effect on respiratory rate. The difference in the mean response between salbutamol and placebo was -0.1 breaths $/ \mathrm{min}(95 \%$ CI -1.4 to +1.1 ; NS). The difference in the mean response between ipratropium and placebo was 0.0 breaths $/ \min (95 \% \mathrm{CI}-0.7$ to +0.8 ; NS).

\section{THEOPHYLLINE LEVELS}

The mean serum level of the six patients receiving theophylline was $50.2(15.1) \mathrm{mmol} / \mathrm{l}$ (therapeutic range $45-110 \mathrm{mmol} / \mathrm{l}$ ). This was not correlated with baseline REE which was

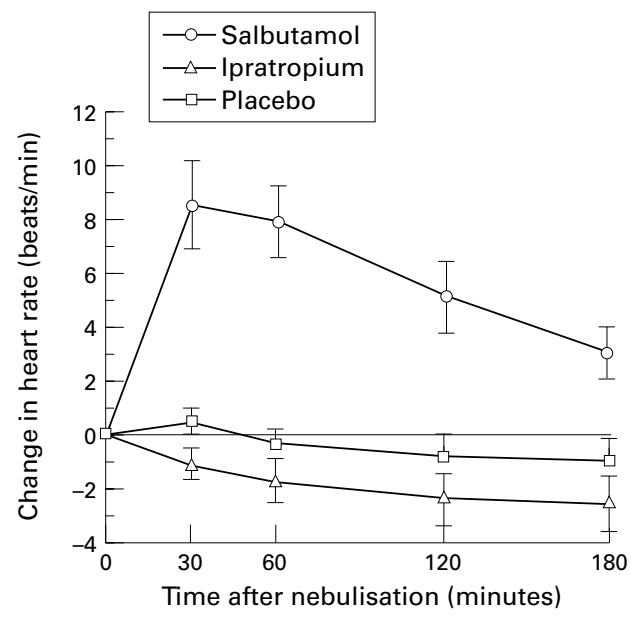

Figure 3 Mean change in heart rate after nebulisation $(n=13)$. Bars $=S E$.

$100.3(5.8) \%$ predicted in patients receiving theophylline and $100.0(4.1) \%$ in those not receiving theophylline $(p>0.9)$. There was no difference in maximal REE after salbutamol between the patients who received theophylline and those who did not.

\section{Discussion}

Theoretically, bronchodilators could have two opposite effects on REE in patients with airway obstruction - firstly an increase in REE due to a direct thermogenic effect ${ }^{28}$ and secondly a decrease in REE due to diminished work of breathing because of bronchodilation.

Our results are consistent with a thermogenic effect of $\beta_{2}$ adrenergic drugs. Compared with placebo, we found a maximal $7.3 \%$ increase in REE 30 minutes after the nebulisation of salbutamol (fig 2) which was sustained with a mean increase of $4.8 \%$ over the 180 minutes of the measurement sessions. The thermogenic effect of sympathetic nervous system stimulation has long been recognised and is mediated by both $\beta_{1}$ and $\beta_{2}$ receptors. ${ }^{28}$ The $\beta$ agonists used as bronchodilators are all $\beta_{2}$ selective and all have similar metabolic effects. Oral terbutaline administered in a dose of $15 \mathrm{mg}$ per day for two weeks in normal subjects increased energy expenditure by $7.7 \%,{ }^{14}$ and $5 \mathrm{mg}$ of salbutamol administered by wet nebulisation increased REE by $8.2 \%$ in patients with cystic fibrosis. ${ }^{29}$ The increase in REE after inhaled salbutamol has recently been found to be dosedependent in normal subjects. ${ }^{11}$ Our results suggest that the effect of salbutamol in patients with COPD is similar to the effect described in normal subjects and patients with cystic fibrosis. However, it is difficult to compare the magnitude of the increase in REE because of the different drugs, doses, and modes of administration used in these studies.

Drug tolerance has not been found with the chronic use of ipratropium, ${ }^{30}$ but it develops with chronic use of $\beta$ agonists. ${ }^{31}$ All our patients were treated with salbutamol on a regular basis. For ethical reasons and in order to study these patients in their usual clinical condition, this 
treatment was continued except for 10 hours before and during the measurement sessions. Despite this regular $\beta_{2}$ adrenergic treatment we were able to measure an increase in REE after salbutamol. This is in agreement with the study cited above ${ }^{14}$ in which an increase in REE in response to an infusion of isoprenaline was still present, although blunted, after two weeks of treatment with terbutaline. In patients with cystic fibrosis ${ }^{29}$ nebulisation of salbutamol also increased REE in the subgroup chronically treated with $\beta_{2}$ agonists, but to a lesser extent than in those not receiving $\beta_{2}$ agonists. This contrasts with a study in normal subjects in which treatment with salbutamol for 13 days prevented an acute thermogenic effect occurring after inhalation of the drug. ${ }^{32}$ Because a certain degree of drug tolerance was likely to be present in our patients, the increase in REE measured after salbutamol could be expected to have been larger if they had not been receiving regular treatment with $\beta_{2}$ agonists or if we had interrupted this treatment earlier.

The relative increase in heart rate and in REE followed a similar time course (peak at 30 minutes) but was of a different magnitude (figs 2 and 3). This could be explained by two distinct effects of salbutamol - a chronotropic effect mediated by $\beta$ receptors of the heart and a thermogenic effect whose mechanism is not fully elucidated but which is likely to be related to skeletal muscle. ${ }^{11}$ The measured increase in heart rate is probably not clinically relevant, but it confirms a metabolic effect of salbutamol by a method independent of calorimetry. The fact that the heart rate increased despite chronic treatment with $\beta_{2}$ agonists argues against a dissociation between the downregulation of the thermogenic and cardiac effects of the drug. ${ }^{32}$

In contrast, ipratropium bromide has no thermogenic effect and, as expected, we found no increase in energy expenditure after ipratropium.

We chose the doses of salbutamol and ipratropium according to the literature. In the three studies comparing the wet nebulisation of these drugs in $\mathrm{COPD}^{22-24}$ the degree of bronchodilation produced by $5 \mathrm{mg}$ of salbutamol or $0.5 \mathrm{mg}$ of ipratropium was equivalent. In our study both drugs induced bronchodilation but with a different time course (fig 1). This is not surprising since the pharmacokinetic properties of the two drugs differ. In view of the total absence of a thermogenic effect of ipratropium the different time course of bronchodilation is not likely to affect our results.

Theophylline causes an increase in REE in normal subjects. ${ }^{13}$ The dose of theophylline prescribed was unchanged three days before the study and during the study and we assumed that the plasma level of the drug was stable. Besides, theophylline does not modify the acute thermogenic response to inhaled salbutamol. ${ }^{13}$ No difference was found in the baseline REE or in the maximal increase in REE after salbutamol between the patients who received theophylline and those who did not.

REE is often higher than predicted in patients with COPD. ${ }^{4-8}$ However, the mean baseline
REE of our patients was not increased. In some studies ${ }^{4-8}$ patients had received bronchodilators before the measurement of REE, possibly leading to an overestimation of true basal metabolism. In addition, the reported baseline REE of our patients was calculated as the mean of the three sessions. REE was 3.5\% higher in the first measurement session than in the last. Taking values from a single measurement session could therefore lead to a slight overestimate of the REE. Finally, there is no evidence that the effects of the bronchodilators on REE would have been different with a higher baseline REE. In our patients there was no correlation between the baseline REE and the maximal increase in REE after salbutamol. Furthermore, the baseline REE values during the measurement sessions with salbutamol, ipratropium, or placebo were the same.

The increase in REE measured in patients with COPD is particularly relevant in underweight patients because it has been cited as the main cause of their malnutrition. ${ }^{10}$ The mean weight of our patients was normal, but among them were two patients who were obese and two who were underweight. The effects of the bronchodilators on $\mathrm{FEV}_{1}, \mathrm{REE}$, and heart rate were similar in the obese subgroup, the underweight subgroup, and in the remaining patients (data not shown). This suggests that the thermogenic effect of salbutamol is independent of nutritional status, although the small number of patients in each group does not allow one to draw definite conclusions.

Are our results clinically relevant? The increase in REE after the nebulisation of $5 \mathrm{mg}$ salbutamol was maximal at 30 minutes but was sustained with a mean change of $4.8 \%$ over 180 minutes. Assuming that the patients take this high dose every six hours and that the mean increase in REE over this period is 3\%, this excess in energy expenditure would represent about $16000 \mathrm{kcal}$ over a year, or the energy equivalent of $1.8 \mathrm{~kg}$ of fat. It should be noted, however, that the increase in REE due to bronchodilator treatment could be compensated by changes in other factors contributing to the total energy balance such as a decrease in activity induced energy expenditure or an increase in food intake. As the thermogenic effect of salbutamol is dose-dependent, ${ }^{11}$ a smaller dose would induce a lesser increase in REE. In addition, it is difficult to compare the dose delivered by wet nebulisation with that by other methods of administration such as metered dose inhalers.

In conclusion, the nebulisation of salbutamol, but not ipratropium bromide, induced a sustained increase in the REE of patients with COPD treated with bronchodilators on a chronic basis. The observed thermogenic effect of $\beta_{2}$ agonists does not explain the hypermetabolism frequently present in COPD because hypermetabolism has also been reported after withdrawal of $\beta_{2}$ agonists. However, when added to other factors, it may further disrupt the energy balance.

1 Vandenbergh E, Van De Woestijne KP, Gyselen A. Weight changes in the terminal stages of chronic obstructive pul- 
monary disease: relation to pulmonary function and prognosis. Am Rev Respir Dis 1967;96:556-65.

2 Wilson DO, Rogers RM, Hoffman RM. Nutrition and chronic lung disease. Am Rev Respir Dis 1985;132:134765.

3 Wilson DO, Rogers RM, Wright EC, Anthonisen NR. Body weight in chronic obstructive pulmonary disease. The National Institutes of Health intermittent positive-pressure breathing trial. Am Rev Respir Dis 1989;139:1435-8.

4 Goldstein SA, Thomashow BM, Kvetan V, Askanazi J, Kinney JM, Elwyn DH. Nitrogen and energy relationships in malnourished patients with emphysema. Am Rev Respir Dis 1988;138:636-44.

5 Fitting JW, Frascarolo P, Jéquier E, Leuenberger P. Energy expenditure and rib cage-abdominal motion in chronic obstructive pulmonary disease. Eur Respir F 1989;2:840-5.

6 Lanigan C, Moxham J, Ponte J. Effect of chronic airflow limitation on resting oxygen consumption. Thorax 1990; 45:388-90.

7 Schols AMWJ, Soeters PB, Mostert R, Saris WMH, Wouters EFM. Energy balance in chronic obstructive pulmonary disease. Am Rev Respir Dis 1991;143:1248-52.

8 Hugli O, Frascarolo P, Schutz Y, Jéquier E, Leuenberger $\mathrm{P}$, Fitting JW. Diet-induced thermogenesis in chronic P, Fitting JW. Diet-induced thermogenesis in chronic
obstructive pulmonary disease. Am Rev Respir Dis 1993; 148:1479-83.

9 Donahoe M, Rogers RM, Wilson DO, Pennock BE. Oxygen consumption of the respiratory muscles in normal and in malnourished patients with chronic obstructive pulmonary disease. Am Rev Respir Dis 1989;140:385-91.

10 Muers MF, Green JH. Weight loss in chronic obstructive pulmonary disease. Eur Respir 7 1993;6:729-34.

11 Amoroso P, Wilson SR, Moxham J, Ponte J. Acute effects of inhaled salbutamol on the metabolic rate of normal subjects. Thorax 1993;48:882-5.

12 Hugli O, Schutz Y, Fitting JW. The daily energy expenditure in stable chronic obstructive pulmonary disease. $A m \mathcal{F}$ in stable chronic obstructive pulmonary

13 Dash A, Agrawal A, Venkat N, Moxham J, Ponte J. Effect of oral theophylline on resting energy expenditure in normal oral theophylline on resting energy exp
volunteers. Thorax 1994;49:1116-20.

14 Scheidegger K, O'Connell M, Robbins DC, Danforth EJ. Effect of chronic b-receptor stimulation on sympathetic nervous system activity, energy expenditure and thyroid hormones. F Clin Endocrinol Metab 1984;58:895-903.

15 Metropolitan Life Insurance Company. New weight standards for men and women. New York: Metropolitan Life, 1983.

16 Durnin JVGA, Womersley J. Body fat assessed from total body density and its estimation from skinfold thickness: measurements on 481 men and women aged from 16 to 72 years. Br $\mathcal{F}$ Nutr 1974;32:77-97.

17 Durnin JVGA, Rahaman MM. The assessment of the amount of fat in the human body from measurement of skinfold thickness. Br f Nutr 1967;21:681-9.

18 Kushner RF. Bioelectrical impedance analysis: a review of principles and applications. $\mathcal{f}$ Am Coll Nutr 1992;11 199-209.

19 Schols AMWJ, Wouters EFM, Soeters PB, Westerterp KP. Body composition by bioelectrical impedance analysis compared to deuterium dilution and skinfold anthropometry in patients with chronic obstructive pulmonary disease. Am 7 Clin Nutr 1991;53:421-4.

20 Quanjer PH. Standardized lung function testing. Report of Working Party on standardization of lung function tests. Bull Eur Physiopathol Respir 1983;19:45-51.

21 Bursztein S, Elwyn DH, Askanazi J, Kinney JM. Energy metabolism, indirect calorimetry, and nutrition. Baltimore: Williams and Wilkins, 1989:61-4.

22 Jenkins CR, Chow CM, Fisher BL, Marlin GE. Comparison of ipratropium bromide and salbutamol by aerosolized of ipratropium bromide and salbutamol by
solution. Aust NZ $\mathcal{F}$ Med 1981;11:513-16.

23 Chan CS, Brown IG, Kelly CA, Dent AG, Zimmermann PV. Bronchodilator responses to nebulised ipratropium and salbutamol singly and in combination in chronic and salbutamol singly and in combination in

24 Barnes D, Delaney JC. A comparison of salbutamol and ipratropium in chronic bronchitis and chronic airflow ipratropium in chronic bronchitis and chr

25 Harris JA, Benedict FG. A biometric study of the basal metabolism in man. Washington, DC: Car

26 Glantz SA. Primer of biostatistics. 3rd edn. New York: McGraw-Hill, 1992:91-4

27 Matthews JNS, Altman DG, Campbell MJ, Royston P. Analysis of serial measurements in medical research. $B M \mathcal{F}$ 1990;300:230-5.

28 Blaak E, Van Baak M, Kempen K, Saris W. Role of $\alpha$ - and $\beta$-adrenoreceptors in sympathetically mediated thermogenesis. Am f Physiol 1993;264:E11-17.

29 Vaisman N, Levy LD, Pencharz PB, Tan YK, Soldin SJ, Canny GJ, et al. Effect of salbutamol on resting energy 111:137-9.

30 Gross NJ. Ipratropium bromide. N Engl f Med 1988;319: 486-94.

31 Motulsky HJ, Insel PA. Adrenergic receptors in man. $N$ Engl F Med 1982;307:18-29.

32 Wilson SR, Amoroso P, Moxham J, Ponte J. Modification of the thermogenic effect of acutely inhaled salbutamol by chronic inhalation in normal subjects. Thorax 1993; 48:886-9. 